\title{
Modification and application of cellulose fibers for the transport of carbonate ions
}

\author{
A. G. Gaikwad
}

Received: 17 October 2012/ Accepted: 3 March 2014/Published online: 18 March 2014

(C) The Author(s) 2014. This article is published with open access at Springerlink.com

\begin{abstract}
The chemical modification of cellulose fiber with tartaric acid, 1,10-phenanthroline and magnesium salt has been done. The metal organic frame work chemically attached to polymer fiber is used to explore the transport of carbonate ions. The different parameters such as loading effect of tartaric acid, magnesium metal ion and 1,10phenanthroline ( $0-2.5 \mathrm{mmol} / \mathrm{g}$ range) over cellulose fiber was studied for the transport of carbonate ions. The transport of carbonate, sulfate and nitrate ions through modified cellulose fibers (fiber-supported solid membrane) was investigated in the molar concentration. In order to check the adsorptive reactive transport of $\mathrm{CO}_{2}$, the transport of carbonate ions with/without bubbling of $\mathrm{CO}_{2}$ $(0-10 \mathrm{~mL} / \mathrm{min})$ in the source phase was explored in the receiving phase.
\end{abstract}

Keywords Modified cellulose fiber membrane . Carbonate ion - Tartaric acid - Magnesium metal ion . 1,10-Phenanthroline

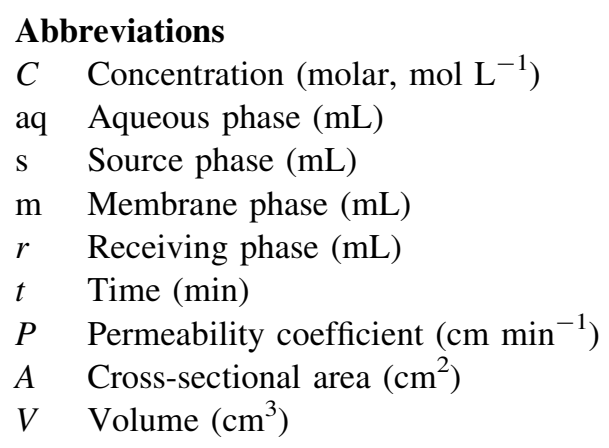

A. G. Gaikwad (两)

CE\&PD Division, National Chemical Laboratory, Pune 411 008, India

e-mail: ag.gaikwad@ncl.res.in

\section{Background}

In the environmental point of view, carbonate ion is one of the most important constituents in the bio-aquatic system. The carbonate ions are formed by reaction of $\mathrm{CO}_{2}$ with gas, solid or liquid state constituents. In other words, $\mathrm{CO}_{2}$ is formed by decomposition of carbonates or burning of organic materials. The important aspects of carbonate ions to explore are the transportation (through solid or liquid or gas) and transformation (from gas to solid or liquid to gas or liquid to solid, and vice versa). Therefore, the transport of carbonate ions through membrane and metal organic work is an important aspect to investigate.

The metal-organic frameworks (MOFs) materials are used for the transportation, transformation, storing, separation and capturing of several gases such as $\mathrm{CO}_{2}, \mathrm{SO}_{2}, \mathrm{NO}_{x}, \mathrm{H}_{2}$, etc., emerging as new adsorbent for $\mathrm{CO}_{2}[1,2]$. However, the metal organic framework (MOF-74) of cobalt, magnesium, nickel, and zinc metals had been successfully used for the separation of ammonia, cyanogen chloride, and sulfur dioxide from air under the humid conditions [3]. For the $\mathrm{CO}_{2}$ capture, supported amine or ionic liquids materials and MOF materials were developed [4]. Moreover, incorporated MOF in fibers by covalent bonding and then using the chemistry of the fiber surface were used to capture the gases. The MOF having ability of hydrogen-bonding donor and acceptor were proved to be effective for the selective removal of gases [5]. However, the anion separations were carried out with MOFs [6]. The chemically modified cellulose fibers were used for the separation and pre-concentration of several metal ions [7]. In plants, the MOF is used to transport and convert the chemical species by using capillary action mechanism. Thus, the MOF chemically fixed (attached) on the polymeric materials could be used to transport and chemically convert the chemical species. $\beta$-Diketones of magnesium form 1:1 
complexes with bidentate ligands such as $2,2^{\prime}$-bipyridine, ethylene glycol and 1,10-phenanthroline. Tris(bipyridine) ruthenium(II) dichloride, $\left[\mathrm{Ru}(\text { bipy })_{3}\right] \mathrm{Cl}_{2}$ hexahydrate, red crystalline salt with distinctive optical properties was explored as catalyst. Photoredox catalysis $\left[\mathrm{Ru}(\mathrm{bipy})_{3}\right]^{2+}$ with visible light adsorption was used for the fine chemical synthesis $[8,9]$. The related $N$-heterocyclic ligand phenanthroline does not have the same conformational flexibility and tends to bind metal ions more strongly [10]. The formation constants for the complexes of $\mathrm{Mg}^{2+}, \mathrm{Ca}^{2+}, \mathrm{Sr}^{2+}$ and $\mathrm{Ba}^{2+}$ with 2,2'-bipyridyl and 1,10-phenanthroline had been determined from $\mathrm{pH}$ measurements in aqueous solution, at $10^{\circ}, 25^{\circ}$ and $40^{\circ}$ and various ionic strengths in the range $0.05-0.95 \mathrm{M}$ [11]. The MOF of the cadmium ion is coordinated with two nitrogen atoms of one 1,10-phenanthroline molecule and five oxygen atoms from three 4,6-dimethyl-5-nitro-isophthalic acid molecules [12]. The partially fluorinated metal-organic frameworks (F-MOFs) had been reported under the different solvothermal conditions $\left[\mathrm{H}_{2} \mathrm{O}\right.$ or $\mathrm{N}, \mathrm{N}$-dimethylformamide (DMF)] from transition metal cations [ $\mathrm{Zn}(\mathrm{II}), \mathrm{Co}(\mathrm{II})$, and $\mathrm{Mn}$ (II)], 1,10-phenanthroline (phen), and 4,4'-(hexafluoroisopropylidene) bis(benzoic acid) $\left(\mathrm{C}_{17} \mathrm{H}_{10} \mathrm{~F}_{6} \mathrm{O}_{4}, \mathrm{H}_{2} \mathrm{hfbba}\right.$ ) to determine the influence of reaction conditions on the formation of metal-organic frameworks [13]. New coordination polymers $\left[\mathrm{Eu}_{2}(\mathrm{TFSA})_{3}(\text { phen })_{2}\right]_{n}$ and $\left[\mathrm{Tb}_{2}(\mathrm{TFSA})_{3}(\text { phen })_{4}\right.$ $\left.\left(\mathrm{H}_{2} \mathrm{O}\right)_{2}\right]_{n}$ (TFSA = tetrafluorosuccinate, phen $=1,10$-phenanthroline) had been reported [14]. An iron-acetate/phenanthroline/zeolitic-imidazolate-framework-derived electro-catalyst with increased volumetric activity and enhanced mass-transport properties had been reported. The zeoliticimidazolate framework serves as a micro-porous host for phenanthroline and ferrous acetate to form a catalyst precursor [15]. Metal organic framework of mononuclear and di-nuclear citrate zinc complex $\left[\mathrm{Zn}(\mathrm{Hcit})(\mathrm{phen})\left(\mathrm{H}_{2} \mathrm{O}\right)\right]\left[\mathrm{Zn}_{2}\right.$ (Hcit)(phen $\left.)_{2}\left(\mathrm{H}_{2} \mathrm{O}\right)_{3}\right] \cdot 13.5 \quad \mathrm{H}_{2} \mathrm{O}$ and its aggregate $\left[\mathrm{Zn}_{3}\right.$ $(\text { Hcit })_{2}$ (phen $\left.)_{4}\right]_{n} \cdot 14 \mathrm{nH}_{2} \mathrm{O}\left(\mathrm{H}_{4}\right.$ cit $=$ citric acid, phen $=1,10$ phenanthroline) were reported by synthesizing through weak acidic solutions. [ $\mathrm{Zn}(\mathrm{Hcit})($ phen $\left.)\left(\mathrm{H}_{2} \mathrm{O}\right)\right]\left[\mathrm{Zn}_{2}(\mathrm{Hcit})(\text { phen })_{2}\right.$ $\left.\left(\mathrm{H}_{2} \mathrm{O}\right)_{3}\right] \cdot 13.5 \mathrm{H}_{2} \mathrm{O}$ was obtained from the reaction of zinc nitrate, citric acid and phenanthroline in a molar ratio of $3: 2: 3$, while a slight excess of phenanthroline results in the formation of the polymeric product $\left[\mathrm{Zn}_{3}(\mathrm{Hcit})_{2}(\text { phen })_{4}\right]_{n} \cdot 14 \mathrm{nH}_{2} \mathrm{O}$ $\left(\mathrm{H}_{4} \mathrm{cit}=\right.$ citric acid, phen $=1,10$-phenanthroline $)$ in a molar ratio of 3:2:4 [16]. Metal organic frameworks using a 1,10-phenanthroline-chelated cadmium complex as precursor and a bridging polycarboxylate as linker had been reported. The reaction of $\mathrm{Cd}\left(\mathrm{NO}_{3}\right)_{2} \cdot 4 \mathrm{H}_{2} \mathrm{O}$ with the chelating ligand 1,10-phenanthroline (phen) at room temperature gave $\left[\mathrm{Cd}(\mathrm{phen})\left(\mathrm{NO}_{3}\right)_{2}\right]$ in high yield. Treatment of the inorganic precursor $\left[\mathrm{Cd}(\right.$ phen $\left.)\left(\mathrm{NO}_{3}\right)_{2}\right]$ with the polycarboxylate bridge ligand, benzene-1,4-dicarboxylic acid $\left(\mathrm{H}_{2} \mathrm{BDC}\right)$ or benzene1,2,4,5-tetracarboxylic acid $\left(\mathrm{H}_{4} \mathrm{btec}\right)$, under mild hydrothermal conditions led to the formation of two metal organic networks $\{[\mathrm{Cd}(\mathrm{BDC})(\text { phen })] \cdot \mathrm{DMF}\}_{n}$ and $\left[\mathrm{Cd}_{2}(\mathrm{btec})\right.$ (phen) $\left.{ }_{2}\right]_{n}$ [17]. However, polymerized highly porous MOF also adsorbs the gases.

In this work, therefore, an attempt has been made to attach the 1,10-phenanthroline through magnesium metal ion to the cellulose tartrate framework. The transport of carbonate ion was explored through fiber-supported solid membrane containing cellulose tartrate, magnesium ion, and 1,10-phenanthroline. For the adsorptive reactive transport studies of $\mathrm{CO}_{2}, \mathrm{CO}_{2}$ was bubbled through the aqueous source solution.

\section{Methods}

Used materials and methods

The stock solutions were prepared by using distilled and de-ionized water. The pretreated cellulose porous solid fibers were (Aldrich Chemicals) obtained for the chemical modification. The standard solution for the analysis of carbonate was prepared from the sodium carbonate (Merck Chemicals). The standardization of carbonate ion was done either by acid-base titration or ion selective electrode depending on the carbonate ion concentrations. Carbonate ions were prepared by bubbling $\mathrm{CO}_{2}$ in aqueous solution and then carbonate ions were standardized by standard methods. The magnesium metal ion was determined by EDTA titration, precipitation and flame photometry depending on concentration. Tartaric acid was estimated by acid-base titration. 1,10-Phenanthroline or 2,2'-bipyridine was determined by acid-base titration or spectro-photometry depending on concentration. The carbonate ion concentration in the cell of the source and receiving solutions was determined with respect to time.

Chemical modification of cellulose fiber

Porous solid fibers were used with dimensions, diameter $0.027 \mathrm{~cm}(270 \mu \mathrm{m})$, porosity $30-50 \%$ and cross-sectional area $5.73 \times 10^{-4} \mathrm{~cm}^{2}$. The cellulose fibers were modified chemically as follows:

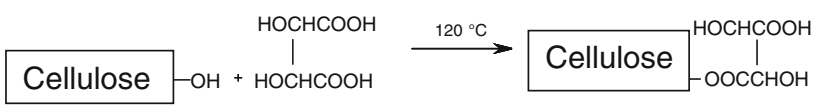

The pretreated cellulose fibers were treated with $0.5 \mathrm{M}$ tartaric acid at a ratio of $1: 12 \mathrm{w} / \mathrm{v}$ of cellulose fiber/acid with stirring for $30 \mathrm{~min}$. Then the slurry was placed in a stainless steel reactor and dried at $50{ }^{\circ} \mathrm{C}$ in a forced air oven for $24 \mathrm{~h}[18,19]$. The thermo-chemical esterification of tartaric acid and cellulose fibers was carried out by heating in an oven at $120{ }^{\circ} \mathrm{C}$ for $90 \mathrm{~min}$. The esterified 


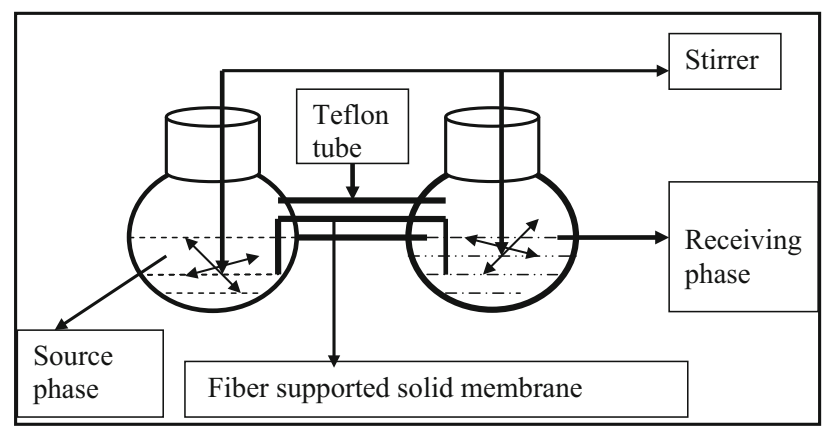

Fig. 1 The schematic presentation of fiber-supported solid membrane cell

cellulose fibers were washed with distilled water until the filtrate was free from tartaric acid which was detected as no turbidity with $0.1 \mathrm{M}$ lead (II) nitrate solution. Then, the esterified cellulose fibers were converted to $\mathrm{Mg}^{2+}$ form by stirring with an aqueous magnesium salt. The excess magnesium metal ion was removed by washing thoroughly with distilled water. The wet modified cellulose fibers were dried at $50{ }^{\circ} \mathrm{C}$ for $24 \mathrm{~h}$. The modified tartarate magnesium cellulose fibers were treated with 1,10-phananthrolone and excess 1,10-phananthrolone was removed by washing thoroughly with distilled water and then acetone. The characterization of the prepared membrane was done as described earlier [5-19].

\section{Designed cell}

The fiber-supported solid membrane cell was used to measure the permeability coefficient $(P)$ (Fig. 1). The membrane cell consists of two round compartments. The modified fibers were used with the fiber diameter $0.027 \mathrm{~cm}(270 \mu \mathrm{m})$ and porosity $30-50 \%$. The cross-sectional area of porous fibers was $5.73 \times 10^{-4} \mathrm{~cm}^{2}$. The amount of aqueous solution in the cellulose porous fibers was calculated by weighing the cellulose porous fibers before and after soaking in the aqueous solution. The Teflon tube with od 0.4 and id $0.2 \mathrm{~cm}$ was used for supporting the cellulose porous solid fibers. The glass tube with inner diameter $0.6 \mathrm{~cm}$ was used for connecting the source and receiving flasks. The level of the glass tube is maintained such that there is no continuous flow of mobile phase either from the source or the receiving phase through the fiber-supported solid membrane.

\section{Results and discussion}

Mechanism of transport of carbonate ions

The MOF was designed and reported for the different applications such as fluorescence, phosphorescence, luminescence, gas separation, gas capturing and sequestration

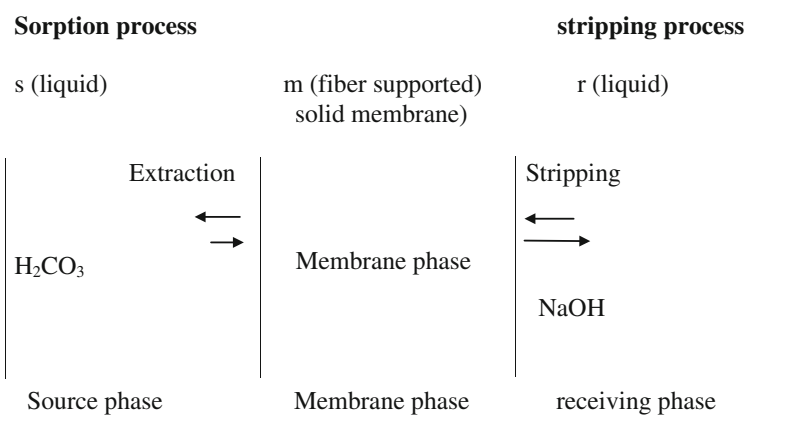

Fig. 2 The illustration of transport of carbonate ions through fibersupported solid membrane

[5-17]. However, the MOF could be used to transport the cations or anions. For the proposed transport of carbonate ion transport mechanisms, the transport of carbonate ions from source to receiving through fiber-supported solid membrane is illustrated in Fig. 2. There is no continuous flow of mobile phase either from source or receiving phase through the fiber-supported solid membrane. The capillary action mechanism in the porous fiber helps to maintain the liquid in the fiber during the transport of carbonate ions. However, there is transport of carbonate ions from the source through the membrane to the receiving phase due the driving forces of the receiving phase. Moreover, the ion exchange and diffusion of chemical species through the fiber-supported solid membrane are the important parameters responsible for the transport of carbonate ions. In the fiber-supported solid membrane, chemically bonded tartaric acid, magnesium metal ion and 1,10-phenanthroline to cellulose fibers is used as the membrane barrier in between the source and the receiving phase. The driving forces of alkali concentration in the receiving phase enhance the transport of carbonate ion.

For the calculation of permeability coefficient $(P)$, the rate of change of concentration of carbonate ion $\left(C^{\mathrm{s}}\right)$ in the source phase or the receiving phase with respect to time $(t)$ through a cross-sectional area $(A)$, volume of source phase $\left(V_{\mathrm{s}}\right)$, fiber column membrane phase length $(l)$ and $k$ a rate constant were given by following the equations [20].

$-\mathrm{d} C^{\mathrm{s}} / \mathrm{d} t=k A /\left(V_{\mathrm{s}} l\right) C_{0}^{\mathrm{s}}$

$\mathrm{d} C^{\mathrm{r}} / \mathrm{d} t=k A /\left(V_{r} l\right) C_{0}^{\mathrm{r}}$

By integrating Eqs. (1) and (2), the permeability coefficient $(P)$ of transport of carbonate ions is given by Eqs. $(3,4)$.

$\operatorname{Ln}\left(C_{\mathrm{t}}^{\mathrm{s}} / C_{0}^{\mathrm{s}}\right)=-\left(A / V_{\mathrm{s}}\right)(P / l) t$

$\operatorname{Ln}\left(C_{\mathrm{t}}^{\mathrm{r}} / C_{0}^{\mathrm{r}}\right)=\left(A / V_{\mathrm{r}}\right)(P / l) t$

The calculated permeability coefficient $(P)$ is used to interpret the data of transport of carbonate ions through 
porous solid fiber-supported solid membrane for the different experimental conditions.

The reactions occurred in the fiber-supported solid membrane system given are the anion exchange of carbonate ions from source solution through membrane (R-N, tartaric acid through magnesium and 1,10-phenanthroline bonded to cellulose) to the receiving phase $(\mathrm{NaOH})$.

$$
\begin{aligned}
& \mathrm{HHCO}_{3, \mathrm{~s}}+\mathrm{R}-\mathrm{N}, \mathrm{m} \\
& \quad \rightarrow \mathrm{R}-\mathrm{N}-\mathrm{H}-\mathrm{HCO}_{3, m} \quad \text { (extraction) } \\
& \mathrm{R}-\mathrm{N}-\mathrm{H}-\mathrm{HCO}_{3, \mathrm{~m}}+2 \mathrm{NaOH}, \mathrm{r} \\
& \quad \rightarrow \mathrm{R}-\mathrm{N}_{, \mathrm{m}}+\mathrm{Na}_{2} \mathrm{CO}_{3, \mathrm{r}}+2 \mathrm{H}_{2} \mathrm{O}_{, \mathrm{r}} \text { (stripping) }
\end{aligned}
$$

Transport of carbonate ion with respect to time

In order to present the transport of carbonate ions through fiber-supported solid membrane from the source to the receiving solution, the permeability coefficient $(P)$ was estimated. Therefore, for the presentation of carbonate ion permeability coefficient, the carbonate ion concentration in the source and the receiving phase with respect to time was determined. From the slope of the plots of $\log \left(C_{\mathrm{t}} / C_{0}\right)$ vs. $t$, the permeability coefficient $(P)$ was determined by using the values of $A\left(5.73 \times 10^{-4} \mathrm{~cm}^{2}\right.$, cross-sectional area), $V(15 \mathrm{~mL}$, volume $)$ and $1(2 \mathrm{~cm}$, length $)$ for the further experiments. The plots of $\log \left(C_{\mathrm{t}} / C_{0}\right)$ with respect to time are given in Fig. 3.

Effect of stirring of bulk phases on the transport of carbonate ion

In order to equalize the diffusion rate of chemical species and chemical reaction rate for the transport of carbonate ions from the source to the receiving phase, the stirring of bulk source and receiving phases are essential to minimize the diffusion layer in between the interfaces for the chemical species in bulk solution and also solution in the fibers. There is no continuous flow of mobile phase either from source or receiving phase through the fiber-supported solid membrane. The capillary action mechanism in the porous fiber helps to maintain the liquid in the fiber during the transport of carbonate ions. However, there is a transport of carbonate ions from the source through the membrane to receiving phase due the driving forces of receiving phase. Therefore, there is a need for stirring of the bulk source and receiving phases. Source and receiving bulk phases were stirred in the range from 50 to $140 \mathrm{rpm}$. In Table 1 , the variable $\log P$ values with stirring of bulk phases in rpm are given. The permeability coefficient $P$ is increased with the increased rpm until 120 . In the range of rpm $120-140$, there is no change in $\log P$ values. However, further experimental studies were carried out at $125 \mathrm{rpm}$.

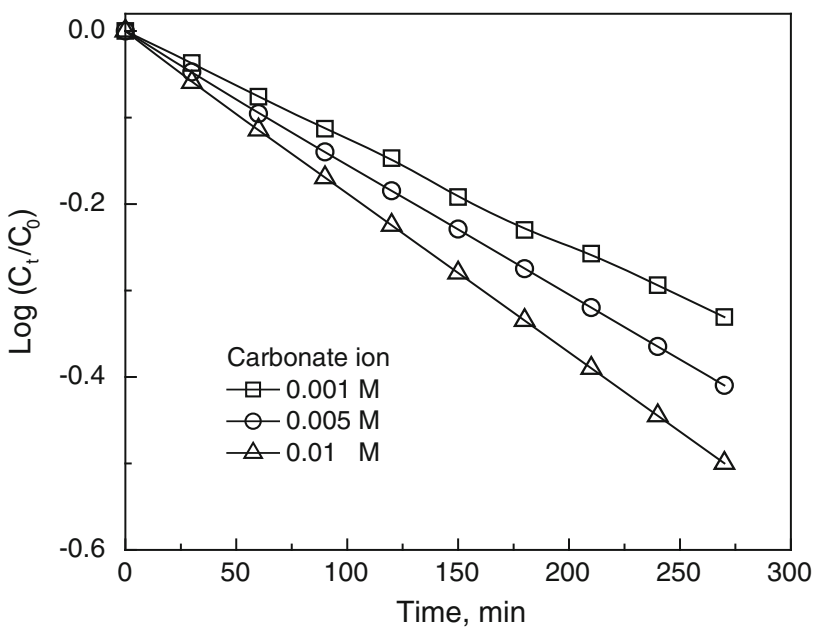

Fig. 3 The effect of concentration variation of carbonate ions with time, $\mathrm{NaOH}=0.05 \mathrm{M}$

Effect of fiber membrane length on the transport of carbonate ions

The transport of carbonate ions depends on the length of membrane fiber, concentration in the source and the receiving phase, stripping agent in the receiving phase. Since, fiber membrane length is one of the factors affecting the transport of carbonate ions, it was explored. The fibersupported solid membrane length determines the time required for travelling of the chemical species. Therefore, the fiber-supported solid membrane length is an important parameter to explore. The fiber membrane length is varied in between 1 and $10 \mathrm{~cm}$ (Fig. 4). $\log P$ decreases with increase in membrane fiber length.

Effect of $\mathrm{NaOH}$ concentration of receiving phase on transport of carbonate ions

The concentration and nature of stripping agents in the receiving phase are the influencing factors for the transport of carbonate ions. $\mathrm{NaOH}$ is used as a stripping agent in the receiving phase. $\mathrm{NaOH}$ concentration in the receiving phase was varied from 0.0001 to 0.01 M. In Fig. 5, log $P$ values against the concentration of $\mathrm{NaOH}$ are given. The increased $\mathrm{NaOH}$ concentration in the receiving phase enhances the transport of carbonate ions in the receiving phase.

Effect of tartaric acid-Mg-1,10-phenanthroline loading on cellulose fiber

The tartaric acid-Mg-1,10-phenanthroline solid membrane phase is fixed on the cellulose fiber. The chemically bonded tartaric acid-Mg-1,10-phenanthroline was varied by 
Table 1 The effect of stirring speed (in rpm) on $\log P$ values for carbonate ion transport, carbonate ion $=0.001 \mathrm{M}$ and $\mathrm{NaOH}=0.01 \mathrm{M}$

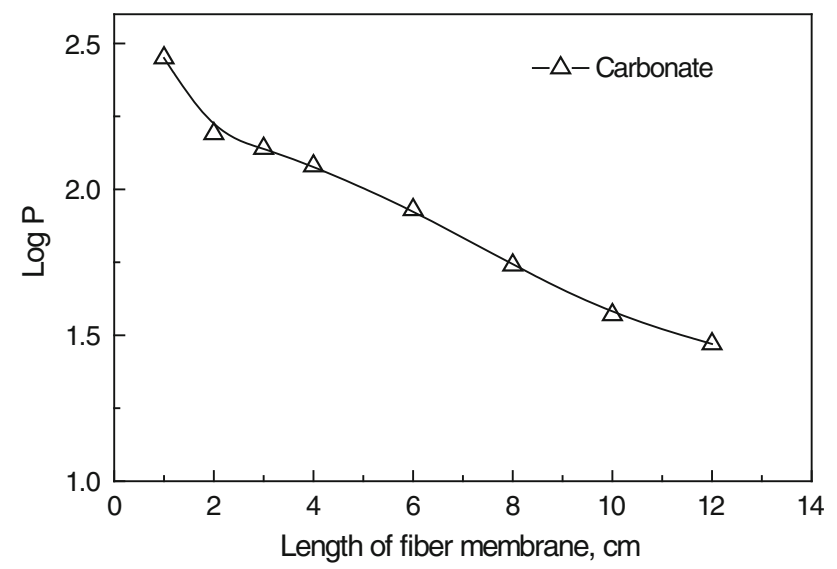

Fig. 4 The effect of fiber membrane length on $\log P$, carbonate $=0.001 \mathrm{M}$ and $\mathrm{NaOH}=0.05 \mathrm{M}$

the means of chemical reaction over cellulose fibers. In Fig. 6, the transports of carbonate ions with the variation of loading of tartaric acid-Mg-1,10-phenanthroline over the cellulose fibers are given. The observed results show that the $\log P$ value increases with the increase in the loading of tartaric acid-Mg-1,10-phenanthroline over the cellulose fibers.

Enrichment of carbonate ion

The proposed supported fiber membrane system has an added advantage for the pre-concentration of carbonate ions from the dilute solutions. Therefore, the enrichment (EF is an enrichment factor which is a ratio of carbonate ion concentrations at time in the receiving to source phase) of carbonate ion from dilute solution was explored with the variation of carbonate ion in source solution. In Table 2, the enrichment factor (EF) with respect to carbonate ion concentration in the source solution is given. The EF value is higher at low concentration of carbonate ion used in source solution. The higher EF values indicate that the enrichment of carbonate ion could be carried out from the dilute solution by uphill transport mechanism.

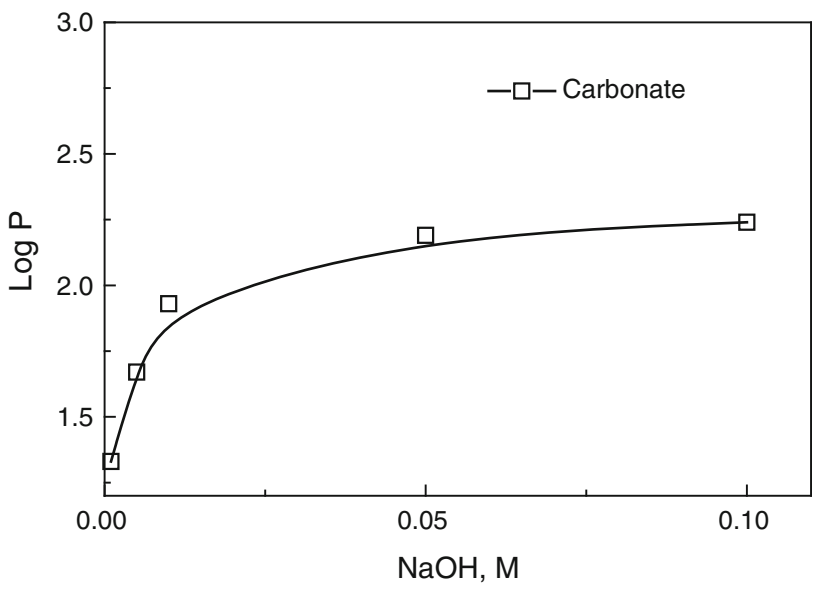

Fig. 5 The effect of $\mathrm{NaOH}$ concentration in receiving phase on $\log P$

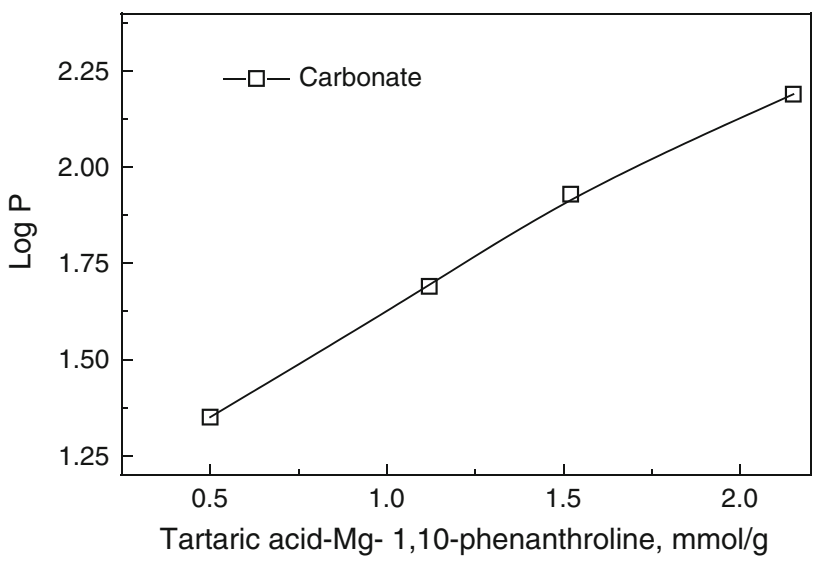

Fig. 6 The effect of loading of tartaric acid-Mg-1,10-phenanthroline on $\log P$, carbonate $=0.001 \mathrm{M}$ and $\mathrm{NaOH}=0.1 \mathrm{M}$

Transport of carbonate, sulfate and nitrate ions

Generally, carbonate, sulfate and nitrate ions are associated with each other in the several samples. In order to check the selective transport of anions, transport of carbonate, nitrate and sulfate ion was investigated. In Fig. 7, the results of transport of carbonate, sulfate and nitrate ions are given. The results show that the carbonate ions are transported faster than the sulfate and nitrate ions.

\section{Effect of passing of $\mathrm{CO}_{2}$ in source phase}

In order to achieve the adsorptive reactive transport of $\mathrm{CO}_{2}$ through fiber-supported solid membrane, some experiments were carried out by bubbling the $\mathrm{CO}_{2}$ through source solution with different flow rates such as $0,1,2,4,6,8$, and $10 \mathrm{~mL} / \mathrm{min}$. The permeability coefficients of carbonate ions with and without passing of $\mathrm{CO}_{2}$ were examined. In Table $3, \log P$ values are given for the carbonate ion 
Table 2 The effect of carbonate ion concentration in source solution on EF values, $\mathrm{NaOH}=0.01 \mathrm{M}$

\begin{tabular}{ll}
\hline Log [carbonate] & EF \\
\hline-6 & 2.62 \\
-5 & 2.15 \\
-4 & 1.95 \\
-3 & 1.62 \\
-2 & 1.59 \\
\hline
\end{tabular}

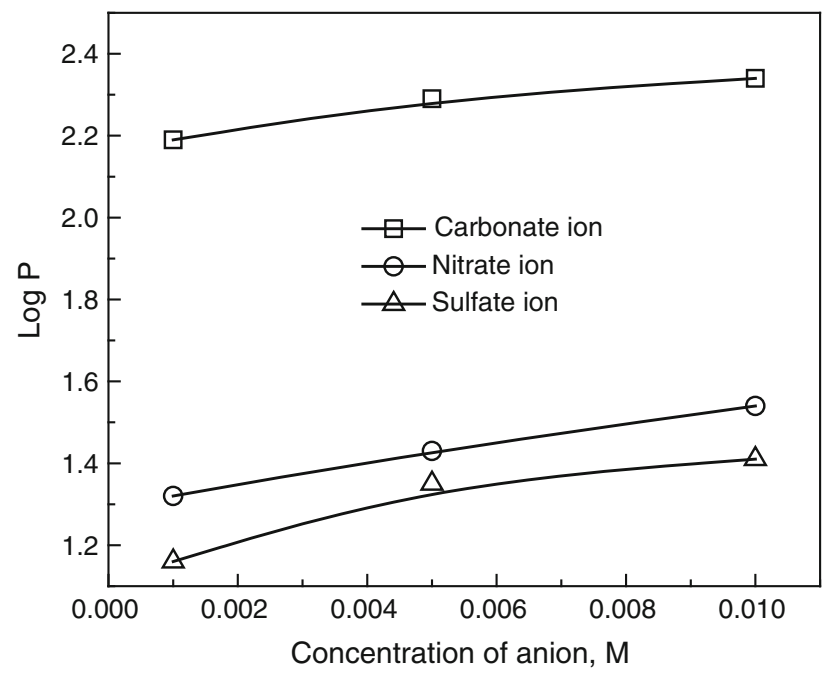

Fig. 7 The $\log P$ values for carbonate, nitrate and sulfate anions, $\mathrm{NaOH}=0.01 \mathrm{M}$

concentration in presence or absence of passing $\mathrm{CO}_{2}$ through source phase. The results show that $\mathrm{CO}_{2}$ bubbling in the source solution increases the $\log P$ values for the carbonate ions. These results indicate that the adsorptive reactive transport of $\mathrm{CO}_{2}$ occurred.

$\log P$ values for the different metal-ligand complexes

Different metal complexes such as 1,10-phenanthroline-iron, 1,10-phenanthroline-manganese, 1,10-phenanthroline-cobalt, 1,10-phenanthroline-copper, 1,10-phenanthroline-zinc, 1,10-phenanthroline-ruthenium, 1,10-phenanthroline-rhodium, 1,10-phenanthroline-platinum, 2,2'-bipyridine-iron, 2,2'-bipyridine-manganese, 2,2'-bipyridine-cobalt, $2,2^{\prime}$-bipyridine-copper, 2,2'-bipyridine-zinc, 2,2'-bipyridineruthenium, 2,2'-bipyridine-rhodium and 2,2'-bipyridineplatinum were attached to the cellulose tartarate. The log $P$ values of carbonate ion transported were determined (Table 4). The results indicate the cellulose tartarate-metal ion-1,10-phenanthroline or cellulose tartarate-metal ion$2,2^{\prime}$-bipyridine complexes transported the carbonate ion from source through the membrane to the receiving phase.
Table 3 The effect of $\mathrm{CO}_{2}$ flow rate on $\log P$, carbonate $=0.001$ (initial) $\mathrm{M}$ and $\mathrm{NaOH}=0.05 \mathrm{M}$

\begin{tabular}{ll}
\hline $\mathrm{CO}_{2}(\mathrm{~mL} / \mathrm{min})$ & $\log P$ \\
\hline 0 & 2.19 \\
1 & 2.31 \\
2 & 2.40 \\
4 & 2.52 \\
6 & 2.64 \\
8 & 2.81 \\
10 & 2.99 \\
\hline
\end{tabular}

Table 4 The effect of loading of tartaric acid-metal ion-1,10-phenanthroline and tartaric acid-metal ion-2,2'-bipyridine on the $\log P$, carbonate $=0.001 \mathrm{M}$ and $\mathrm{NaOH}=0.05 \mathrm{M}$

Loading of cellulose-tartaric acid-metal ion-1,10phenanthroline, or cellulose-tartaric acid-metal ion-2,2' $\log$ bipyridine complex, $2.15 \mathrm{mmol} / \mathrm{g}$

\begin{tabular}{ll}
\hline Cellulose-tartaric acid-iron-1,10-phenanthroline & 2.25 \\
Cellulose-tartaric acid-manganese-1,10-phenanthroline & 2.16 \\
Cellulose-tartaric acid-cobalt-1,10-phenanthroline & 2.18 \\
Cellulose-tartaric acid-copper-1,10-phenanthroline & 2.25 \\
Cellulose-tartaric acid-zinc-1,10-phenanthroline & 2.39 \\
Cellulose-tartaric acid-ruthenium-1,10-phenanthroline & 2.42 \\
Cellulose-tartaric acid-rhodium-1,10-phenanthroline & 2.41 \\
Cellulose-tartaric acid-platinum-1,10-phenanthroline & 2.43 \\
Cellulose-tartaric acid-iron-2,2'-bipyridine & 2.32 \\
Cellulose-tartaric acid-manganese-2,2'-bipyridine & 2.14 \\
Cellulose-tartaric acid-cobalt-2,2'-bipyridine & 2.13 \\
Cellulose-tartaric acid-copper-2, 2 -bipyridine & 2.25 \\
Cellulose-tartaric acid-zinc-2,2'-bipyridine & 2.38 \\
Cellulose-tartaric acid-ruthenium-2,2'-bipyridine & 2.42 \\
Cellulose-tartaric acid-rhodium-2,2'-bipyridine & 2.39 \\
Cellulose-tartaric acid-platinum-2, $22^{\prime}$-bipyridine & 2.42 \\
\hline
\end{tabular}

\section{Experimental}

Estimation of carbonate ion concentration

The source solution with a suitable carbonate ion concentration was used in $15 \mathrm{~mL}$ in the source compartment of the cell. The receiving phase $15 \mathrm{~mL}$ with appropriate concentration of sodium hydroxide was used in the receiving compartment of the cell. The source and receiving solutions were connected with fiber-supported solid membrane through a Teflon tube. Some of the experiments were carried out with/without the presence of $\mathrm{CO}_{2}$ with a flow rate of $0,1,2,4,6,8,10 \mathrm{~mL} / \mathrm{min}$ in the source phase. The samples of the source and receiving solutions were analyzed with respect to time. 


\section{Conclusions}

Carbonate ion transport studies were done through fibersupported solid membrane. Transport of carbonate ions was studied with variation of different experimental parameters such as stirring of bulk phase, membrane length, MOF, etc. Carbonate ions are transported faster than sulfate and nitrate ions. The adsorptive reactive transport of $\mathrm{CO}_{2}$ was observed through fiber-supported solid membrane which is useful for the adsorptive separation of $\mathrm{CO}_{2}$. Fiber-supported solid membrane technique could be used for the transport or selective removal or recovery or separation of metal ions and also anions from the geological sites such as in mining industries.

Conflict of interest The author declares that author has no competing interests.

Open Access This article is distributed under the terms of the Creative Commons Attribution License which permits any use, distribution, and reproduction in any medium, provided the original author(s) and the source are credited.

\section{References}

1. Canioni R, Roch MC, Sécheresse F, Horcajada P, Serre C, Hardi DM, Férey G, Jean MG, Frédéric L, Jong SC, Young KH, Oleg L, Stuart T, Gustaaf VT (2011) Stable polyoxometalate insertion within the mesoporous metal organic framework MIL-100(Fe). Mater Chem 21:1226-1233

2. Atci E, Erucar I, Keskin S (2011) Adsorption and transport of $\mathrm{CH}_{4}, \mathrm{CO}_{2}, \mathrm{H}_{2}$ mixtures in a bio-MOF material from molecular simulations. J Phys Chem C 115:6833-6840

3. Qian RF, Da QY, Julian S, Jian RL, Zheng BH, Hong CZ (2010) Functional mesoporous metal-organic frameworks for the capture of heavy metal ions and size-selective catalysis. Inorg Chem 49(24):11637-11642

4. Jones $\mathrm{CW}$ (2011) $\mathrm{CO}_{2}$ capture from dilute gases as a component of modern global carbon management. Annu Rev Chem Biomol Eng 2:31-52

5. Klein N, Senkovska I, Gedrich K, Stoeck U, Henschel A, Mueller U, Stefan K (2009) A mesoporous metal-organic framework. Angew Chem Int Edn 48(52):9954-9957

6. Wang C, Xie Z, Edekrafft K, Lin W (2011) Doping metal-organic frameworks for water oxidation, carbon dioxide reduction, and organic photocatalysis. J Am Chem Soc 133(34):13445-13454
7. Furukawa H, Ko N, Bok GY, Aratani N, Beom CS, Choi E, Yazaydin A, Snurr RQ, Okeeffe M, Kim J, Omar M (2010) Ultrahigh porosity in metal-organic frameworks. Science 329(5990):424-428

8. Sungur S, Babglu S (2005) Synthesis of a new cellulose ion exchanger and use for the separation of heavy metals in aqueous solutions. Sep Sci Technol 40(10):2067-2078

9. Teply F (2011) Photoredox catalysis by $\left[\mathrm{Ru}(\mathrm{bpy})_{3}\right]^{2+}$ to trigger transformations of organic molecules. Organic synthesis using visible-light photocatalysis and its 20th century roots. Collect Czechsvakia Chem Commun 76(7):859-917

10. Neumann M, Füldner S, König B, Zeitler K (2011) Metal-free, cooperative asymmetric organophotoredox catalysis with visible light. Angew Chem Int Edn 50(4):951-954

11. Capone S, Derobertis A, Destefano C, Scarcella RR (1985) Thermodynamics of formation of magnesium, calcium, strontium and barium complexes with 2,2'-bipyridyl and 1,10-phenanthroline, at different ionic strengths in aqueous solution. Talanta 32(8):675-677

12. Yu MU, Xiao LZ, Tuo PH (2010) Synthesis, structure and thermal stability of a cadmium coordination polymer $[\mathrm{Cd}(\mathrm{phen})(4,6-$ dimethyl-5-nitro-isophthalic Acid)]n. Chin J Struct Chem 30(10):1442-1446

13. Pachfule P, Dey C, Panda T, Vanka K, Banerjee R (2010) Structural diversity in partially fluorinated metal organic frameworks (F-MOFs) composed of divalent transition metals, 1,10Phenanthroline, and fluorinated carboxylic acid. Cryst Growth Des 10(3):1351-1363

14. Xia L, Yan BZ, Mei S, Pei ZL (2008) Poly[[triaqua- $\left(\mu_{3}-4-o x-\right.$ idopyridine-2,6-dicarboxyl-ato)terbium(III)] monohydrate]. Inorg Chem Commun 11(8):869-872

15. Eric P, Frederic J, Michel L, Nicholas L, Juan T, Juan H, Jean PD (2011) Iron-based cathode catalyst with enhanced power density in polymer electrolyte membrane fuel cells. Nature Commun 2. doi: $10.1038 /$ ncomms 1427

16. Rong HZ, Wen SX, Hongxin W, Zhao HZ (2009) Metal-organic frameworks constructed from monomeric, dimeric and trimeric phenanthroline citrate zinc building units. Inorg Chem Commun 12(6):583-587

17. Jing YW, Che HC, Tien WT, Kuang LL (2006) Synthesis of twodimensional metal organic networks from 1,10-phenanthrolinechelated cadmium complex and polycarboxylate. J Mol Struct 796(1-3):69-75

18. Wong KK, Lee CK, Low KS, Haron MJ (2003) Removal of $\mathrm{Cu}$ and $\mathrm{Pb}$ by tartaric acid modified rice husk from aqueous solutions. Chemosphere 50:23-28

19. Wong KK, Lee CK, Low KS, Haron MJ (2003) Removal of $\mathrm{Cu}$ and $\mathrm{Pb}$ from electroplating wastewater using tartaric acid modified rice husk. Proc Biochem 39:437-445

20. Ochromowicz K, Apostoluk W (2010) Modelling of carrier mediated transport of chromium (III) in the supported liquid membrane system with $\mathrm{D}_{2}$ EHPA. Sep Purif Technol 72:112-117 